\title{
Teaching Magnetism in High School
}

\author{
Fengfeng Zhou, Kyle Routzong
}

University of Cincinnati/Hughes High School

\section{Introduction}

According to statistics from the Third International Mathematics and Science Study (TIMSS) ${ }^{1}$ conducted in 1995, U.S. students ranked above the international average in the $4^{\text {th }}$ grade and dropped to the middle in $8^{\text {th }}$ grade for their mathematics and science achievement. Alarmingly, the performance of U.S. $12^{\text {th }}$ graders ranked among the lowest scoring nations in the same study. Four years later, the 1999 TIMSS-Repeat showed that no change occurred in $8^{\text {th }}$-grade math and science achievement (students in the $4^{\text {th }}$ and $12^{\text {th }}$ grades were not tested in TIMSS-R). To address this issue and cope with the rapid advancement in science and technology, National Science Foundation (NSF) has funded a number of research projects at dozens of universities nationwide. One of these projects is Science and Technology Enhancement Program (STEP) currently being conducted at the University of Cincinnati. Project STEP involves nine graduate and eight undergraduate fellows, twenty-two secondary science and mathematics teachers, and ten UC professors (from the College of Engineering and College of Education). Every fellow is placed in a secondary school to work with one or more teachers. The main responsibility of a fellow is to develop and implement hands-on activities that are technology-driven and inquirybased. Activities are incorporated into lessons, demonstrations, laboratory exercises, and field experiences. By doing these activities, students will experience authentic scientific and engineering research practices that require higher-order thinking skills and creative problemsolving skills. This will enable each student to develop a better understanding of science and engineering and hopefully foster a desire to advance his/her education in a related field.

The authors, as participants of project STEP, developed a module to teach magnetism to seniors at Hughes High School in Cincinnati, Ohio. The overall objective of this module was to increase student interest in physics and engage them in the learning process. To this end, technology was incorporated in each activity as much as possible. The module included three sessions. Each session lasted 1.5 hours and contained two hands-on activities. These activities aligned with the science and math standards of Ohio and were designed to be attractive and challenging to students. All lectures for this module were delivered with PowerPoint slides. Most slides contain one or two pictures to illustrate the content being covered. A website (ffz2.tripod.com) was developed to present students with interesting applications of magnetism such as MRI (magnetic resonance imaging) and maglev (magnetically lifted train). Students took two quizzes, one before and one after the implementation of the module. They were also given an opportunity to evaluate the module, the implementation, and the performance of the instructor. 
The six activities involved setting and observing a magnetic field, investigating the performance of an electromagnet, verifying the formula $\mathrm{F}=\mathrm{BIL}$, constructing an electric motor, conducting electromagnetic induction, and investigating the performance of a transformer. Among them, the formula-verification activity was found to be the most innovative and challenging. This activity will be described in detail.

\section{Description}

As mentioned above, the third activity in the magnetism module is both creative and challenging. It is suitable for juniors as well as seniors. The lesson plan for this activity is presented below.

Objectives:

\section{Magnetic Force}

1. Students will experience authentic scientific/engineering research practice that requires higher-order thinking skills.

2. Students will make a scientific inquiry and construct a logical verification.

3. Students will understand that a magnetic field exerts a force on any current-bearing object.

4. Students will be able to apply various measurement scales to describe phenomena and solve problems.

5. Students will be able to draw conclusions from their inquiries, use the third right-hand rule and the formula $\mathrm{F}=\mathrm{BIL}$ to solve relevant problems.

6. Students will understand the nature of the magnetic force and be able to determine the force exerted on an electric charge in a magnetic field.

Materials:

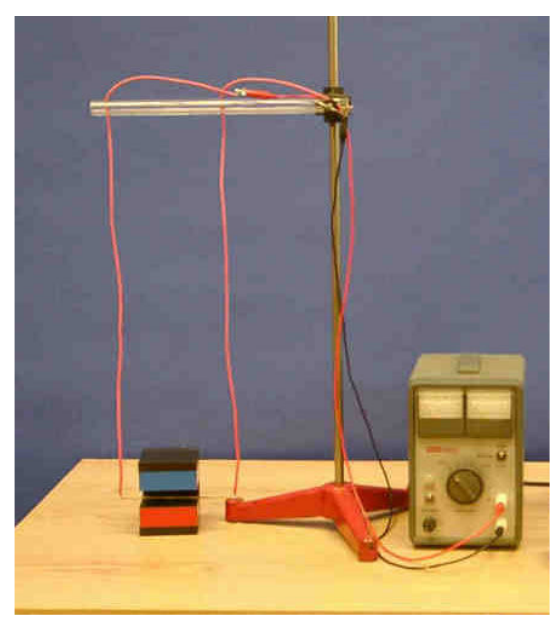

A power supply with maximum voltage output less than $12 \mathrm{~V}$, a sensor to measure magnetic induction, a "trapeze" as shown in Figure 1 , four alligator connectors, four leads, a strong horseshoe magnet, a ruler, and a steel tape.

Figure 1. A "trapeze"

Procedures:

1. Introduce the identity --- magnetic induction (B) and its units Tesla and Gauss. 
2. Demonstrate that a magnetic field will exert a force on electric current-bearing object.

3. Ask students to connect the trapeze and power supply, then turn on the power and set the current (I) to $1 \sim 2 \mathrm{~A}$. Due to the magnetic force (F) exerted on the copper pipe, the pipe will be pushed away from its initial position. Ask students to measure the distance the pipe moved and compute the swing angle between the current and initial position of the pipe. With the angle known and the weight of the pipe given to students, they should be able to calculate the magnetic force (F) exerted on the pipe. The steps and free body diagram are given to students as shown in Figure 2.

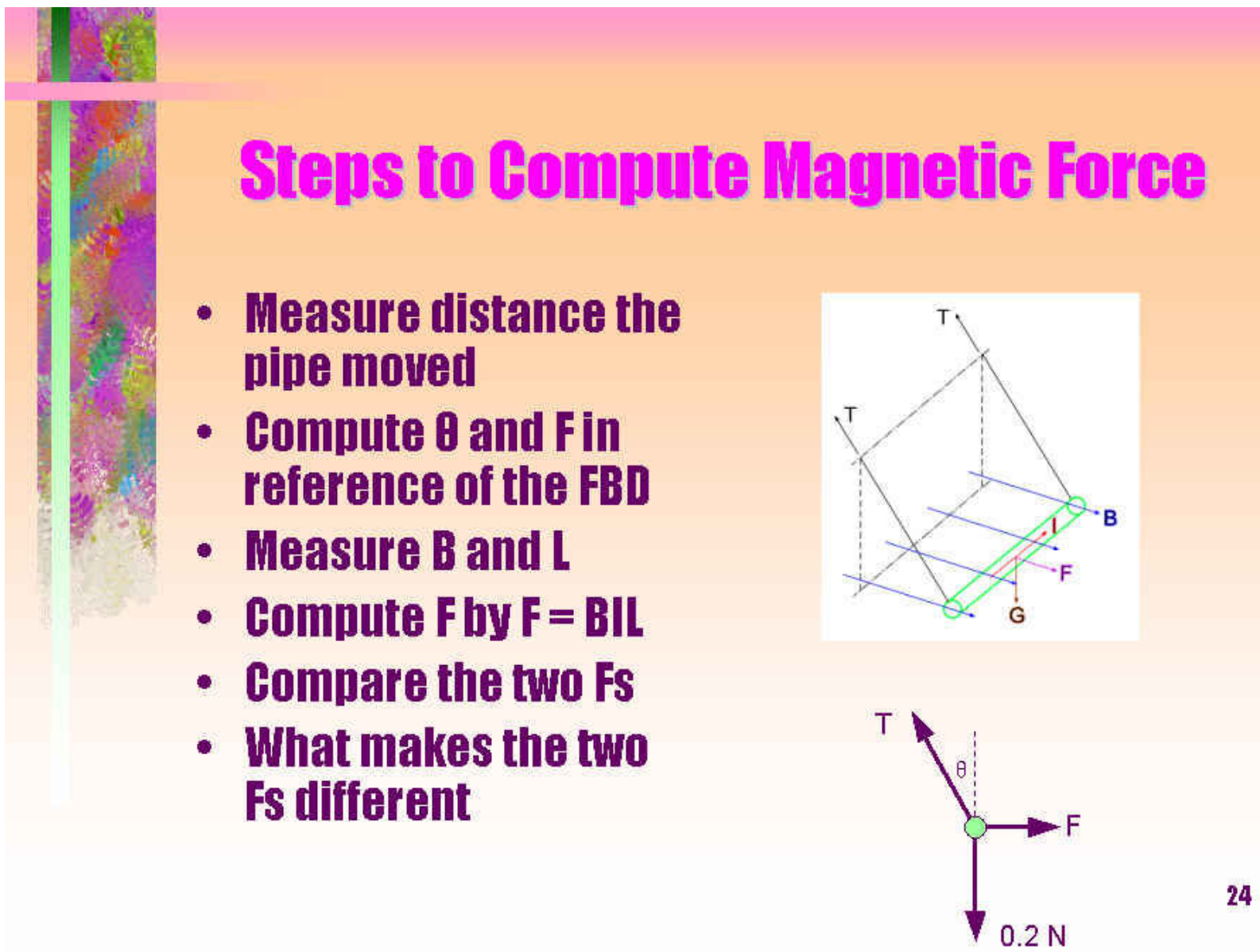

Figure 2. Illustration of Step 3

4. Explain to students how to use the sensor correctly.

5. Ask students to measure the magnetic induction (B) of the magnetic field using the sensor, read the value of current strength (I) from the power supply, and measure the proper length $(\mathrm{L})$ of the pipe which can be taken as the width of the magnet.

6. Ask students to compute the product of B, I, and L. Ask them to compare the product with $\mathrm{F}$. If the difference is significant, ask them which value is more dependable, and also ask them to identify sources of error.

7. Tell students the formula to calculate magnetic force $(F)$ in terms of B, I, and L.

8. Project a graph to illustrate the relationship of directions of $\mathrm{B}, \mathrm{I}$, and $\mathrm{F}$ and introduce the third right-hand rule. 
9. Tell students the magnetic force exerted on current is the resultant force exerted on all charged particles forming the current. Derive the formula to calculate the force $(\mathrm{F})$ exerted on any charge (q) by a magnetic field (B): $F=q v B$ where $v$ is the speed at which the charge moves.

10. Ask students to give examples of use of magnetic force. Present several slides to show applications of magnetic force which students may not know. Tell student that exerting a force on any current is the most important property of a magnetic field and the most important application of this property is the invention of electric motors.

\section{Discussion}

Not only was this activity popular with the students, it was found to be successful in a number of other aspects as well. First, it aligns with many of Ohio's science, math, and technology standards. In other words, it embodies the required approach to teaching. Second, it offers an opportunity for students to conduct authentic scientific research and combine their knowledge of mechanics and mathematics to reinforce their learning. Third, it is attractive and students were found to be quite engaged in carrying out the investigation. This not only benefits student learning in the short term, it also confers a long lasting effect we hope will benefit them in their future study of science and engineering. Finally, it is challenging and can be easily modified to become even more challenging. For example, most students did not know how to measure the distance the pipe moved and the length of the wire supporting the pipe because they could not determine the correct reference points. To make this activity more challenging, one option would be not telling students that F has a linear relationship with B, I, and L. Instead, they could be required to determine the relationship between F and B, F and I, and so on. A drawback of this activity is that it requires a device to measure magnetic induction that may not be available at many schools. On the other hand, the use of such a device is an effective way to introduce sophisticated technology into secondary classrooms and should be encouraged whenever possible.

Dr. Anant Kukreti, Director of Project STEP, observed the implementing of Activity 3 and 4. "These activities are excellent," he said immediately after the class. Students' reflections on the whole module are also encouraging according to a survey. All 15 students in the class took part in the survey. Among them, 4 students rated the module to be "excellent", 7 rated it "very good", the remaining results include 1 "good", 2 "fair", 1 "poor", and 0 "very poor". Considering the fact that the instructor is not a teacher and not a native speaker, these results should be regarded as very positive.

Generally, students are more interested in doing hands-on activities rather than other activities that are not hands-on. However, this does not necessarily mean that they will learn more and better by just doing these activities. In fact, most students tend to play around for fun only without much thinking and reasoning if they are not directed to. Hence, well-prepared guidance should be provided so that students will do the activities in a well-organized manner, finish all requirements in time, and grasp the principles embedded in the activities. Moreover, good activities should be attractive and challenging. While attractiveness is the key to keep students 
busy, challenge is the key to make students think in higher order and better understand the subject matter.

Needless to say, designing creative hands-on activities takes a lot of time. But teachers usually do not have a lot of time to design innovative activities. Even if a teacher can find some time to develop a few good activities, it is hard for him/her to do so for a whole course. So, if a teacher develops just one activity and put it in a database available to all teachers free of charge, it must be a valuable resource for teachers. Since a teacher just needs to make one high quality lesson plan, every teacher should be able to find the time to finish the job. If teachers nationwide all contribute to the database, the database will have thousands or hundreds of thousands of activities. The authors hope that professional organizations such as National Council of Teachers of Mathematics (NCTM), and National Science Teachers Association (NSTA) will sponsor such a campaign and maintain the database. This will benefit teachers, and then students, the education, and the society.

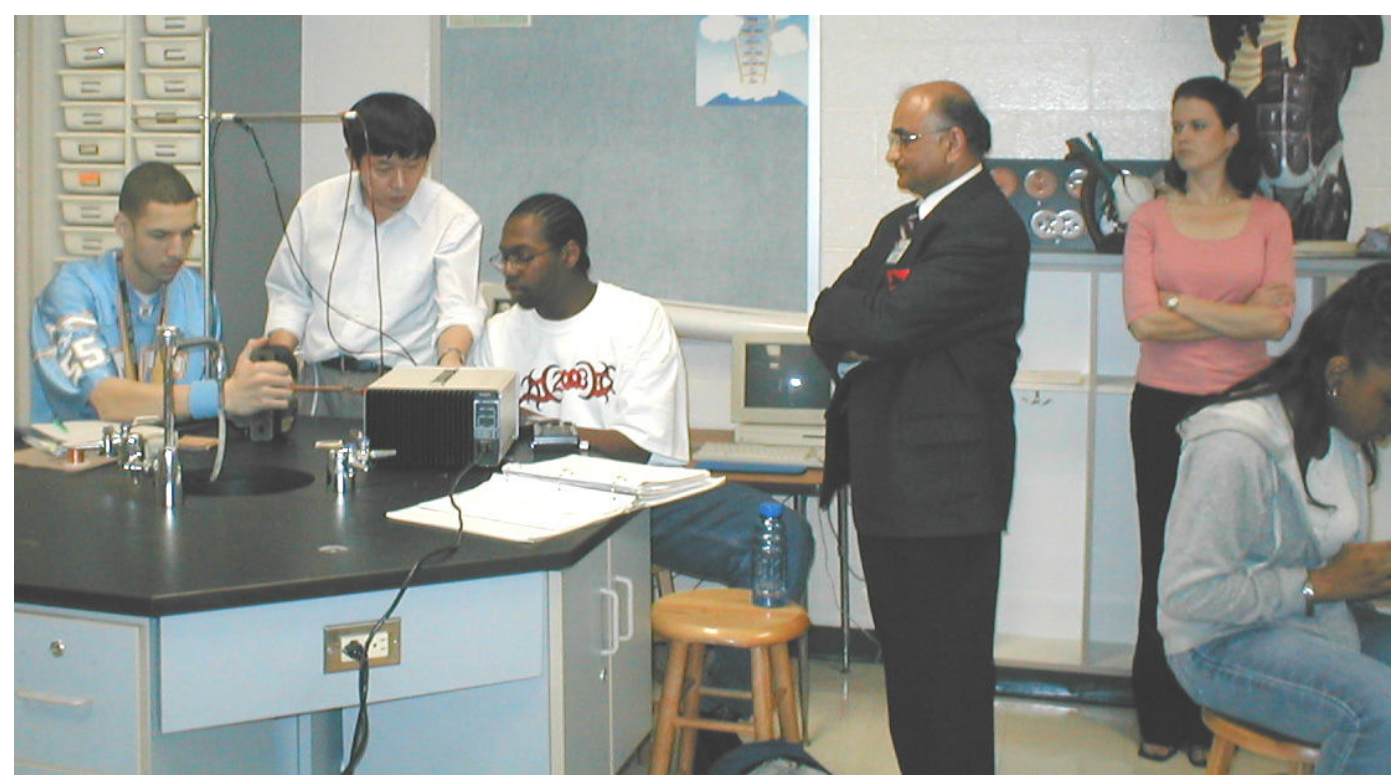

Figure 3. Dr. Anant Kukreti observing class

\section{Bibliography}

1. International Study Center, Third International Mathematics and Science Study (TIMSS), 1995, $<$ http://timss.bc.edu $>$

\section{Biographical Information}

FENGFENG ZHOU is a Ph.D. student in civil engineering at the University of Cincinnati. His undergraduate major is physics. He holds master's degree in civil engineering. His dissertation research is to develop a computer program to simulate the elastoplastic behavior of endplate connections in steel building frames. He was an assistant professor at Shandong University of Science and Technology, China before coming to the USA.

KYLE ROUTZONG teaches Engineering Physics at Hughes High School in Cincinnati, Ohio. 